\title{
Pt-Au/C cathode with enhanced oxygen-reduction activity in PEFCs
}

\author{
G SELVARANI, S VINOD SELVAGANESH, P SRIDHAR* ${ }^{*}$ S PITCHUMANI and A K SHUKLA ${ }^{\dagger}$ \\ CSIR-Central Electrochemical Research Institute-Madras Unit, CSIR Madras Complex, Chennai 600 113, India \\ ${ }^{\dagger}$ Solid State and Structural Chemistry Unit, Indian Institute of Science, Bangalore 560 012, India
}

MS received 27 September 2010; revised 20 December 2010

\begin{abstract}
Carbon-supported Pt-Au (Pt-Au/C) catalyst is prepared separately by impregnation, colloidal and micro-emulsion methods, and characterized by physical and electrochemical methods. Highest catalytic activity towards oxygen-reduction reaction (ORR) is exhibited by $\mathrm{Pt}-\mathrm{Au} / \mathrm{C}$ catalyst prepared by colloidal method. The optimum atomic ratio of $\mathrm{Pt}$ to $\mathrm{Au}$ in $\mathrm{Pt}-\mathrm{Au} / \mathrm{C}$ catalyst prepared by colloidal method is determined using linear-sweep and cyclic voltammetry in conjunction with cell-polarization studies. Among 3:1, 2:1 and 1:1 Pt-Au/C catalysts, (3:1) Pt-Au/C exhibits maximum electrochemical activity towards ORR. Powder X-ray diffraction pattern and transmission electron micrograph suggest Pt-Au alloy nanoparticles to be well dispersed onto the carbon-support. Energy dispersive $\mathrm{X}$-ray analysis and inductively coupled plasma-optical emission spectroscopy data suggest that the atomic ratios of the alloying elements match well with the expected values. A polymer electrolyte fuel cell (PEFC) operating at $0.6 \mathrm{~V}$ with $(3: 1) \mathrm{Pt}-\mathrm{Au} / \mathrm{C}$ cathode delivers a maximum power-density of $0.65 \mathrm{~W} / \mathrm{cm}^{2}$ in relation to $0.53 \mathrm{~W} / \mathrm{cm}^{2}$ delivered by the PEFC with pristine carbon-supported Pt cathode.
\end{abstract}

Keywords. Polymer electrolyte fuel cells; cathode catalyst; platinum-gold alloy; oxygen-reduction reaction.

\section{Introduction}

Polymer electrolyte fuel cells (PEFCs) are being perceived as promising alternative power source for various mobile and stationary power applications due to their high efficiency, quick start-up and low operating-temperature. However, the extent of oxygen-reduction kinetics at cathode in PEFCs happens to be several orders lower than the hydrogen-oxidation kinetics at the anode, which leads to a higher over-potential at the cathode and to consequent reduction in performance and efficiency of the PEFCs (Bockris and Srinivasan 1969; Gottesfeld and Zawodzinski 1997). Accordingly, a PEFC cathode-electrocatalyst that can ameliorate oxygen-reduction reaction (ORR) is much desired for PEFCs.

Owing to the acidic nature of polymer-membrane electrolyte and low-temperature operation of PEFCs, the use of non-noble catalysts has met only a limited success (Fernandez et al 2005; Shao et al 2006a, b). At present, platinum (Pt) is widely used as a catalyst in PEFCs, due to its high activity towards ORR. However, $\mathrm{Pt}$ is expensive and its resources are limited. Furthermore, the activity of Pt towards ORR remains much lower than is desired due to high activation-overvoltage (Gasteiger et al 2005). In the literature (Antolini et al 2005; Lima et al 2006; Yuan et al 2006; Gong et al 2007), addition of base metals, such as iron, cobalt, nickel, chromium, to $\mathrm{Pt}$ is known to ameliorate ORR. However, the resulting Pt-base metal alloy catalysts exhibit poor long-term stability due to the dissolution of transition metal (Pourbaix 1974).

*Author for correspondence (psridhar55@gmail.com)
Accordingly, efforts are being made to find a long-lasting and active catalyst for PEFCs. In this context, introduction of second noble metal, such as palladium, gold, to Pt has received considerable attention in recent years due to their attractive stability and activity towards ORR in fuel cells (Li et al 2004; Shao et al 2006a, b; Hernandez-Fernandez et al 2007; Mathiyarasu and Phani 2007). Among the various noble metals, gold is of particular interest in view of its inertness in the bulk state but high catalytic activity at nano-scales. Janssens et al (2006) reported a dramatic increase in the catalytic activity with gold particles $<5 \mathrm{~nm}$ which has also been corroborated by El-Deab and Osaka (2002a, b, 2003).

Pristine $\mathrm{Au}$ as electrocatalyst has been intensively investigated for fuel cell applications and different methods of preparation for $\mathrm{Au}$ nanoparticles and their performance towards ORR have been reported in the literature (Haruta 1997; Berg et al 1998; El-Deab and Osaka 2002a, b; Xu and Mavrikakis 2003). The electrocatalytic behaviour of $\mathrm{Au}$ nanoparticles is attributed to an enrichment of the step orientation of the Au surface that is considered to be an active reaction-site for ORR (El-Deab and Osaka 2002a, b). However, the electrocatalytic activity of Au still stands lower than Pt. Accordingly, it is not feasible to replace Pt with pristine $\mathrm{Au}$ as electrocatalyst.

Generally, the rate-determining step for ORR is the splitting of the $\mathrm{O}=\mathrm{O}$ bond to form water. The kinetics of reaction depends on the degree of interaction of oxygen with catalystadsorption sites. The guidelines for designing bimetallic catalysts suggest that one of the metals in the bimetal catalyst should facilitate the splitting of $\mathrm{O}=\mathrm{O}$ bond while the 
other should help reduce the adsorbed atomic-oxygen (Luo et al 2006). In this context, the combination of $\mathrm{Pt}$ and $\mathrm{Au}$ has been found to be superior to pristine Pt towards ORR (Elhsissen et al 1999; Devarajan et al 2005; Luo et al 2005; Njoki et al 2005; Qian et al 2006; Hernandez-Fernandez et al 2008; Wang et al 2008, 2009; Liu et al 2009a, b; Ma et al 2010). In view of the unique properties of nano-sized gold (Haruta 2005; Hughes et al 2005; Luo et al 2006) and the high catalytic-activity of $\mathrm{Pt}$, bimetallic $\mathrm{Pt}-\mathrm{Au}$ nanoparticles of optimum composition are highly likely to serve as synergistic catalysts. It is also reported that the intra-alloy charge transfer from $\mathrm{Pt}$ to $\mathrm{Au}$ in the $\mathrm{Pt}-\mathrm{Au}$ alloy catalyst increases the extent of $d$-orbital vacancy in Pt (Goodenough et al 1989; Berg et al 1998). Accordingly, Pt-Au nanoparticle is expected to be synergistic to ORR at the PEFC cathode. In the literature, silica-supported $\mathrm{Pt}-\mathrm{Au}$ nanoparticles have been studied intensively (Luo et al 2006; Mott et al 2007). Several authors (Hernandez-Fernandez et al 2007, 2008; Wang et al 2008, 2009; Liu et al 2009a, b; Ma et al 2010) have reported the influence of catalyst preparation of bimetallic Pt-Au nanoparticles on ORR. Although high activity of Pt-Au catalyst towards ORR is claimed, its performance in fuel cells remains limited and the effect of varying $\mathrm{Pt}$ to $\mathrm{Au}$ ratio in the $\mathrm{Pt}-\mathrm{Au}$ alloy catalyst on ORR remains unexplored.

In the present study, $\mathrm{Pt}-\mathrm{Au} / \mathrm{C}$ catalyst is prepared separately by impregnation, colloidal and micro-emulsion methods and the optimum catalyst composition is established by linear-sweep voltammetry (LSV) in conjunction with cell-polarization studies. The extent of alloy formation, mean particle-size and morphology of $\mathrm{Pt}-\mathrm{Au} / \mathrm{C}$ are studied by powder X-ray diffraction (XRD) and transmission electron microscopy (TEM). The bulk and surface compositions of $\mathrm{Pt}$ and $\mathrm{Au}$ in $\mathrm{Pt}-\mathrm{Au} / \mathrm{C}$ catalysts are determined using inductively-coupled-plasma optical emission spectroscopy (ICP-OES) and energy-dispersive analysis by $\mathrm{X}$-rays (EDAX), respectively.

\section{Experimental}

\subsection{Preparation of carbon-supported Pt-Au catalyst}

To prepare $\mathrm{Pt}-\mathrm{Au} / \mathrm{C}$ by the impregnation method, the required amounts of the metal precursors, viz. $\mathrm{H}_{2} \mathrm{PtCl}_{6}$ and $\mathrm{HAuCl}_{4}$, were dissolved in a solution containing water and 2-propanol, and $\mathrm{pH}$ of the solution was adjusted to $\sim 4$ by adding $\mathrm{Na}_{2} \mathrm{CO}_{3}$. The resulting mixture was added drop wise to a dispersion of carbon (Vulcan XC72R) in water under reflux. Subsequently, alkali-stabilized sodium borohyride was added to the mixture and stirred continuously for $3 \mathrm{~h}$. Pt-Au/C catalyst was obtained after filtering and washing with distilled water followed by drying overnight in an air oven at $80^{\circ} \mathrm{C}$.

In the colloidal method, the required amount of hydrogen tetrachloroaurate $\left(\mathrm{HAuCl}_{4}\right)$ solution was added dropby-drop at $40^{\circ} \mathrm{C}$ to a platinum-metal precursor, viz.
$\mathrm{Na}_{2}\left[\mathrm{Pt}\left(\mathrm{SO}_{3}\right)_{4}\right]$, dissolved in acidified water, followed by drop-wise addition of $15 \mathrm{w} / \mathrm{o}$ hydrogen peroxide with continuous stirring at $60^{\circ} \mathrm{C}$ that resulted in vigorous gas evolution. The solution was further stirred for $1 \mathrm{~h}$. Subsequently, the required amount of carbon slurry was added to it. Finally, Pt$\mathrm{Au} / \mathrm{C}$ was obtained by passing hydrogen gas for $2 \mathrm{~h}$ at $80^{\circ} \mathrm{C}$ that was filtered, washed copiously with hot distilled-water, and dried overnight in an air oven at $80^{\circ} \mathrm{C}$.

In the micro-emulsion method, the required amount of metal precursor viz. $\mathrm{H}_{2} \mathrm{PtCl}_{6}$ and $\mathrm{HAuCl}_{4}$, carbon and hydrazine were dissolved separately in micro-emulsion containing sodium bis (2-ethylhexyl sulfosuccinate), water and isooctane. Then, micro emulsion containing the metal precursors was slowly added to micro-emulsion of carbon with constant stirring followed by the addition of microemulsion containing excess of hydrazine with continued stirring overnight. $\mathrm{Pt}-\mathrm{Au} / \mathrm{C}$ was obtained by the addition of tetrahydrofuran that was washed with water/ethanol mixture to remove excess surfactant followed by drying overnight at $80^{\circ} \mathrm{C}$.

\subsection{Electrochemical characterization}

2.2a Half-cell studies: To study the activity of $\mathrm{Pt} / \mathrm{C}$ and $\mathrm{Pt}-\mathrm{Au} / \mathrm{C}$ catalysts, $\mathrm{LSV}$ and $\mathrm{CV}$ measurements were performed using a computer-controlled electrochemical analyser (Autolab PGSTAT-30). For LSV experiments, the electrode rotation speeds were controlled by EcoChemie RDE - 70296 Unit. Glassy carbon (GC) disk was used as the working-electrode substrate in the study. Prior to each experiment, the electrode was polished with $0.06 \mu \mathrm{m}$ alumina to obtain a mirror-finished surface followed by rinsing with distilled water in an ultrasonic bath. To prepare the working electrode, catalyst $(\mathrm{Pt} / \mathrm{C}$ or $\mathrm{Pt}-\mathrm{Au} / \mathrm{C})$ suspension was obtained by adding catalyst to water followed by Nafion ionomer addition and sonication for $30 \mathrm{~min}$. The suspension was quantitatively transferred to the surface of polished GC disk. The electrode was dried at room temperature $\left(\sim 25^{\circ} \mathrm{C}\right)$. A saturated calomel electrode (SCE) and a Pt foil were used as reference and counter electrodes, respectively in the 3-electrode-cell configuration.

In order to clean and activate the working electrode, it was cycled between $-0.25 \mathrm{~V}$ and $0.8 \mathrm{~V}$ with respect to SCE at a sweep rate of $50 \mathrm{mV} / \mathrm{s}$ in de-aerated $\left(0.5 \mathrm{M} \mathrm{H}_{2} \mathrm{SO}_{4}\right)$ electrolyte until stable and reproducible voltammograms were obtained. The cyclic voltammograms were recorded once the working electrode was well equilibrated. LSV experiments were performed using RDE in oxygen saturated aqueous $0.5 \mathrm{M} \mathrm{H}_{2} \mathrm{SO}_{4}$. The concentration of the dissolved oxygen in saturated aqueous $0.5 \mathrm{M} \mathrm{H}_{2} \mathrm{SO}_{4}$ being $\sim 1 \mathrm{mM}$ (Lide 1995). LSV data were recorded in the cathodic-sweep direction at $3 \mathrm{mV} / \mathrm{s}$ between $0.8 \mathrm{~V}$ and $0 \mathrm{~V}$ vs SCE with varying rotations (400-2400 rpm) at room temperature.

2.2b Fuel-cell studies: Fabrication of membrane electrode assemblies (MEAs): MEAs were fabricated as reported 
elsewhere (Selvarani et al 2009a, b). In brief, both anode and cathode contained a backing layer, a gas-diffusion layer and a catalyst layer. A teflonized (15 w/o) carbon paper (Toray-TGP-H-120) of $0.35 \mathrm{~mm}$ thickness was employed as the backing layer to these electrodes. To prepare the gasdiffusion layer, carbon was suspended in cyclohexane and agitated in an ultrasonic water bath for $30 \mathrm{~min}$. To this mixture, 15 w/o Teflon suspension was added under sonication. The resultant slurry was coated onto a teflonized carbon paper followed by sintering at $350{ }^{\circ} \mathrm{C}$ for $30 \mathrm{~min}$.

To prepare the catalyst layer, required amount of $\mathrm{Pt} / \mathrm{C}$ or $\mathrm{Pt}-\mathrm{Au} / \mathrm{C}$ was suspended in isopropyl alcohol. The mixture was agitated in an ultrasonic water bath, and 7 and 30 w/o of Nafion (Dupont) dispersion was added to anode and cathode slurries, respectively with continuing ultrasonication for $30 \mathrm{~min}$. The resulting ink was coated on a gas-diffusion layer. Both anode and cathode contained a platinum loading of $0.5 \mathrm{mg} \mathrm{cm}^{-2}$ (active area, $25 \mathrm{~cm}^{2}$ ) which was kept identical in all the MEAs. To establish effective contact between the catalyst layer and the polymer electrolyte, a thin layer of Nafion ionomer (5 w/o) diluted with isopropyl alcohol in 1:1 ratio was spread onto the surface of each electrode. MEAs were obtained by hot pressing the cathode and anode on either side of a pretreated-Nafion 1135 membrane under a compaction pressure of $60 \mathrm{~kg} \mathrm{~cm}^{-2}$ at $130^{\circ} \mathrm{C}$ for $3 \mathrm{~min}$.

2.2c Cell-polarization studies: MEAs were evaluated using a conventional $25 \mathrm{~cm}^{2}$ fuel-cell fixture with parallel serpentine-flow-field machined on graphite plates obtained from M/s Schunk Kohlenstofftechnik GmbH, Germany. After equilibration, galvanostatic-polarization data for the cells were obtained at $60^{\circ} \mathrm{C}$ at varying load current-densities with humidified hydrogen and oxygen feeds at atmospheric pressure at anode and cathode, respectively, using a LCN100-36 electronic load procured from Bitrode Corporation, US.

\subsection{Physical characterization}

Powder XRD patterns for the catalysts were obtained on a Philips X'Pert Diffractometer using $\mathrm{Cu} \mathrm{K}_{\alpha}$ radiation $(\lambda=$ $1.5406 \AA$ ) between $20^{\circ}$ and $80^{\circ}$ in reflection geometry in steps of $0.034^{\circ} / \mathrm{min}$. The morphology of the catalysts was examined under a TCNAI 20 G2 transmission electron microscope $(200 \mathrm{kV})$ by suspending catalyst particles in isopropyl alcohol and casting the sample by dropping the catalyst solution onto a carbon-coated copper grid followed by solvent evaporation in vacuum at room temperature.

The surface atomic compositions for $\mathrm{Pt}-\mathrm{Au} / \mathrm{C}$ catalysts with varying atomic ratios of $\mathrm{Pt}$ to $\mathrm{Au}$ were obtained with the help of a JEOL JSM 5400 scanning electron microscope coupled with energy dispersive X-ray analysis facility. For this study, the sample was prepared by pressing the catalyst powder onto a conducting carbon-tape pasted onto a copper stub.
ICP-OES was used to analyse the bulk composition of $\mathrm{Pt}$ and $\mathrm{Au}$ in $\mathrm{Pt}-\mathrm{Au} / \mathrm{C}$ catalysts with varying atomic ratios. For this purpose, the catalysts were dissolved in concentrated aqua regia, and subsequently diluted to concentrations ranging between 1 and $50 \mathrm{ppm}$ as desired for the analysis. The actual composition was determined from the calibration curves for the known standards.

In the following text, $\mathrm{Pt}-\mathrm{Au} / \mathrm{C}$ catalyst prepared by impregnation, colloidal and micro-emulsion methods is represented as S-1, S-2 and S-3, respectively along with their atomic ratios as (1:1), (2:1) and (3:1). For example, $\mathrm{Pt}-\mathrm{Au} / \mathrm{C}$ catalyst prepared by colloidal method with atomic ratio $2: 1$ is represented as S-2(2:1) and the carbon-supported Pt catalyst $(\mathrm{Pt} / \mathrm{C})$ is represented as $\mathrm{S}-4$.

\section{Results and discussion}

$\mathrm{Pt}-\mathrm{Au}$ catalyst can be prepared both by chemical and electrochemical routes. But the former is more suitable for bulk preparation. In order to identify the most suitable chemical preparatory-route among impregnation, colloidal and microemulsion methods for $\mathrm{Pt}-\mathrm{Au}$ catalyst, $\mathrm{Pt}-\mathrm{Au}$ (2:1) composition is arbitrarily chosen and powder-XRD patterns for $\mathrm{S}-1$ (2:1), S-2 (2:1) and S-3 (2:1) samples obtained, and compared with the powder XRD pattern for $\mathrm{S}-4$ as shown in figure 1. The XRD pattern for S-2(2:1), S-3(2:1) and S-4 show characteristic peaks of face centred cubic $(f c c)$ crystalline Pt at (111), (200), (220), and (311) reflections. The XRD peak corresponding to (111) plane for Pt in S-4 is observed at $39.7^{\circ}$ and for pure $\mathrm{Au}$ at $38.2^{\circ}$ (Selvarani et al 2009a); Pt (111) reflections for S-2(2:1) and S-3(2:1) catalysts are observed at $38.7^{\circ}$ and $38.8^{\circ}$, respectively. The negative shift in (111) reflection for $\mathrm{S}-2(2: 1)$ and $\mathrm{S}-3(2: 1)$

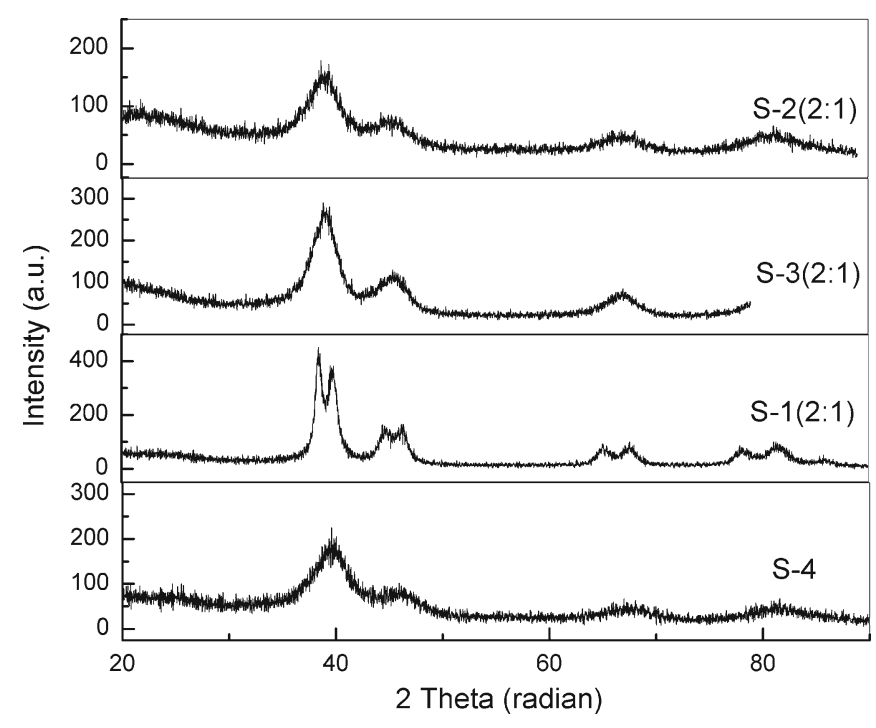

Figure 1. XRD patterns for (S-4) and S-1(2:1), S-2(2:1) and S$3(2: 1)$ catalysts. 


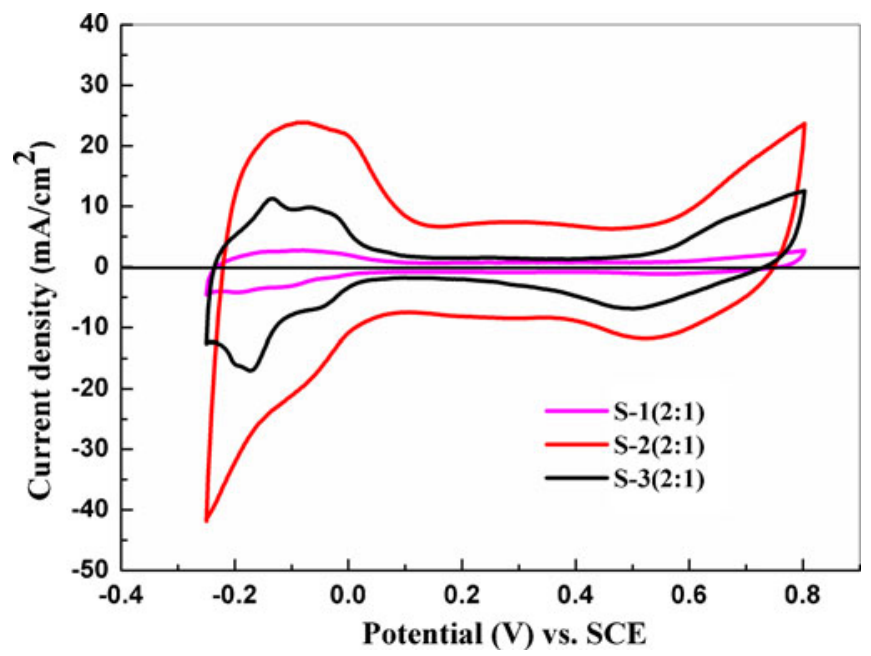

Figure 2. Steady-state cyclic voltammograms for $\mathrm{S}-1(2: 1)$, S$2(2: 1)$ and $\mathrm{S}-3(2: 1)$ catalysts in $\mathrm{N}_{2}$-saturated $0.5 \mathrm{M} \mathrm{H}_{2} \mathrm{SO}_{4}$.

catalysts in relation to S-4 confirms the alloy formation in $\mathrm{Pt}-$ $\mathrm{Au}$ catalysts. By contrast, the presence of (111) reflection at $38.2^{\circ}$ for $\mathrm{Au}$ and $39.6^{\circ}$ for Pt suggests the presence of $\mathrm{Au}$ and $\mathrm{Pt}$ as a physical mixture in S-1(2:1) catalyst. According to the binary phase-diagram, there is a miscibility gap between $\mathrm{Pt}$ and $\mathrm{Au}$, and hence, phase segregation can be expected. Accordingly, appropriate thermal-treatment for the sample is required to obtain $\mathrm{Pt}-\mathrm{Au}$ alloy (Bond 2007).

According to Bond (2007) although Pt-Au phase diagram shows a wide-miscibility gap due to limited solubility of the components, nano-sized particles form homogeneous alloys as all atoms retain their electronic structure, and rehybridization due to band formation is hindered. Hence, a proper synthetic route is desirable for realizing bimetallic Pt$\mathrm{Au}$ nanoparticles. In the literature, $\mathrm{Pt}$ and $\mathrm{Au}$ are reported to be present as individual elements in $\mathrm{Pt}-\mathrm{Au}$ when colloidal method is used for its preparation (Hernandez-Fernandez et al 2007) while, in the present study, solid solutions of $\mathrm{Pt}-\mathrm{Au}$ alloy are obtained by this method, which could be attributed to the precursor and reaction $\mathrm{pH}$ conditions. In the present study, the catalyst S-1(2:1) prepared by impregnation method yields segregated $\mathrm{Pt}$ and Au particles because the reduction of $\mathrm{Au}$-ion proceeds faster than Pt-ion. In the literature, it is reported that the catalyst prepared by impregnation method needs to be heated above $500^{\circ} \mathrm{C}$ in order to obtain alloy while, in the present study, the heat treatment is avoided to preclude the formation of larger particles. In the light of the foregoing, a judicious selection of preparatory conditions, viz. precursor, solution $\mathrm{pH}$, heating rate and the reaction temperature, is mandatory for synthesizing finely-divided $\mathrm{Pt}-\mathrm{Au}$ alloy.

As a surface sensitive technique, $\mathrm{CV}$ detects the electrochemical properties of surface atoms rather than the bulk atoms (Kristian and Wang 2008). In addition, CV is a useful technique to analyse the influence of the particle size of catalyst on electrochemical surface-area (ESA). Steady-state cyclic voltammograms are shown for S-1(2:1), S-2(2:1) and S-3(2:1) catalysts in de-aerated $0 \cdot 5 \mathrm{M} \mathrm{H}_{2} \mathrm{SO}_{4}$ as shown in figure 2. All catalysts display features of hydrogen adsorption-desorption between $-0.24 \mathrm{~V}$ and $0.1 \mathrm{~V}$ vs SCE followed by the "double-layer" region indicative of the presence of Pt component dominating on the surface of the bimetallic catalyst. During the anodic sweep, at potentials $>0.45 \mathrm{~V}$ vs SCE, oxide film formation followed by its removal during the cathodic sweep is observed. The hydrogen adsorption/desorption charge $\left(Q_{\mathrm{H}}\right)$ for the $\mathrm{S}-1(2: 1)$ catalyst is lower than that for $\mathrm{S}-2(2: 1)$ and $\mathrm{S}-3(2: 1)$ catalysts suggesting the ESA to be lower for $S-1(2: 1)$, which is attributed to the larger particles of the catalyst sample in relation to the other two catalysts. The values of $Q_{\mathrm{H}}$ and ESA for all the three catalysts are presented in table 1 . From the powder-XRD patterns, it is clear that the $S-1(2: 1)$ catalyst has segregated $\mathrm{Pt}$ and Au particles; the voltammogram obtained for the catalyst shows characteristic peaks for hydrogen adsorption/desorption, double-layer region followed by oxide formation and reduction on Pt.

In order to analyse the influence of preparation condition on electrochemical activity of $\mathrm{Pt}-\mathrm{Au}$ catalyst towards ORR, LSV study is conducted using RDE in oxygen-saturated aqueous $\mathrm{H}_{2} \mathrm{SO}_{4}$. LSV data are recorded cathodically at $3 \mathrm{mV} / \mathrm{s}$ scan rate between $0.8 \mathrm{~V}$ and $0 \mathrm{~V}$ vs SCE at $1200 \mathrm{rpm}$. Figure 3 shows the ORR data for the S-1(2:1), S-2(2:1) and S-3(2:1) catalysts and their electrode-kinetic parameters, viz. onset potential, kinetic current-density at $0.6 \mathrm{~V}$ vs SCE and mass activity, are given in table 1 . It is seen from these data that the onset potential, kinetic current and mass activities increase as $\mathrm{S}-1(2: 1)<\mathrm{S}-3(2: 1)<\mathrm{S}-2(2: 1)$. Thus, among the

Table 1. Electrokinetic parameters for carbon-supported Pt-Au catalyst with different methods of preparation.

\begin{tabular}{|c|c|c|c|c|c|}
\hline Catalyst & $\begin{array}{c}\text { Charge } \\
Q_{\mathrm{H}}(\mathrm{mC})\end{array}$ & $\begin{array}{l}\text { ESA } \\
\left(\mathrm{m}^{2} / \mathrm{g}\right)\end{array}$ & $\begin{array}{c}\text { Onset } \\
\text { potential } \\
(V \text { vs SCE })\end{array}$ & $\begin{array}{l}\text { Kinetic current } \\
\text { density @ } 0.6 V \text { vs } \\
\text { SCE }\left(\mathrm{mA} / \mathrm{cm}^{2}\right)\end{array}$ & $\begin{array}{c}\text { Mass activity @ 0.6 V } \\
\text { vs SCE (mA/g) }\end{array}$ \\
\hline S-1(2:1) & $11 \cdot 7$ & $11 \cdot 1$ & 0.739 & 0.99 & 1980 \\
\hline S-2(2:1) & $80 \cdot 5$ & $76 \cdot 7$ & 0.752 & 4.64 & 9280 \\
\hline $\mathrm{S}-3(2: 1)$ & 44.8 & $42 \cdot 7$ & 0.742 & $2 \cdot 26$ & 4520 \\
\hline
\end{tabular}


three $\mathrm{Pt}-\mathrm{Au} / \mathrm{C}$ catalysts prepared through different chemical routes, S-2(2:1) catalyst shows enhanced-activity towards ORR.

To validate the performance of various $\mathrm{Pt}-\mathrm{Au}$ catalysts in a typical PEFC system, steady-state polarization curves are obtained with a $\mathrm{H}_{2} \mathrm{O}_{2}$ PEFC employing $\mathrm{Pt}-\mathrm{Au} / \mathrm{C}$ prepared through various methods and the data are presented in figure 4. Among these, $\mathrm{Pt}-\mathrm{Au} / \mathrm{C}$ prepared through colloidal route, viz. $S-2(2: 1)$, exhibits highest activity in the entire polarization region as compared to $S-1(2: 1)$ and $S-3(2: 1)$. These data confirm well with LSV studies. PEFC cathode comprising S-2(2:1) operating at $0.6 \mathrm{~V}$ delivers a powerdensity of $0.63 \mathrm{~W} / \mathrm{cm}^{2}$ in relation to $0.52 \mathrm{~W} / \mathrm{cm}^{2}$ and $0.43 \mathrm{~W} / \mathrm{cm}^{2}$ obtained with PEFC cathodes employing S-3 (2:1) and S-1 (2:1), respectively.

The aforesaid studies clearly indicate that the S-2(2:1) catalyst shows enhanced electrochemical activity towards ORR

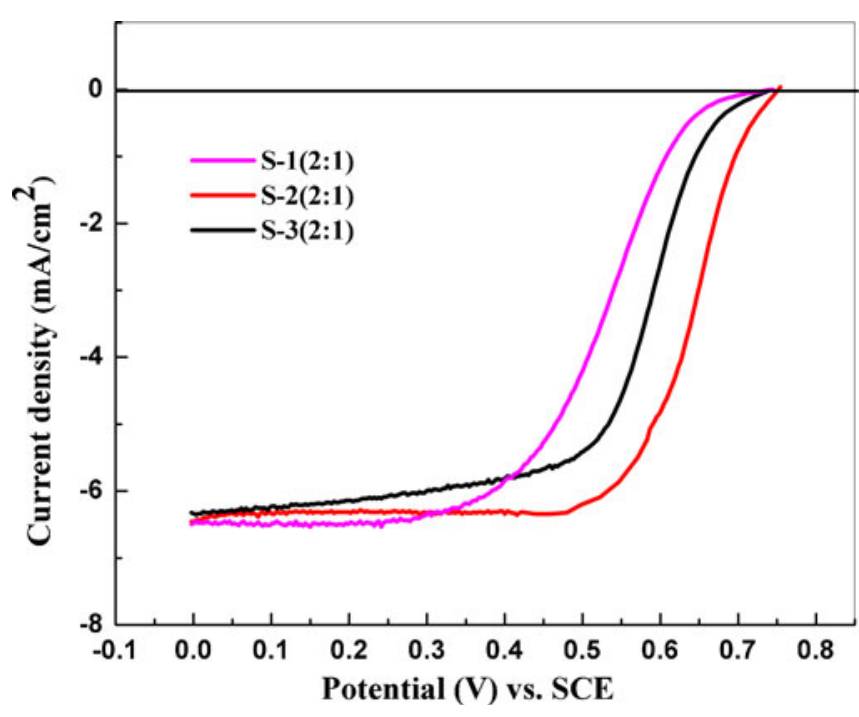

Figure 3. LSV measurements of $\mathrm{S}-1(2: 1), \mathrm{S}-2(2: 1)$ and $\mathrm{S}-3(2: 1)$ catalysts in $\mathrm{O}_{2}$-saturated $0.5 \mathrm{M} \mathrm{H}_{2} \mathrm{SO}_{4}$ for ORR at $1200 \mathrm{rpm}$ with a scan rate of $3 \mathrm{mV} / \mathrm{s}$.

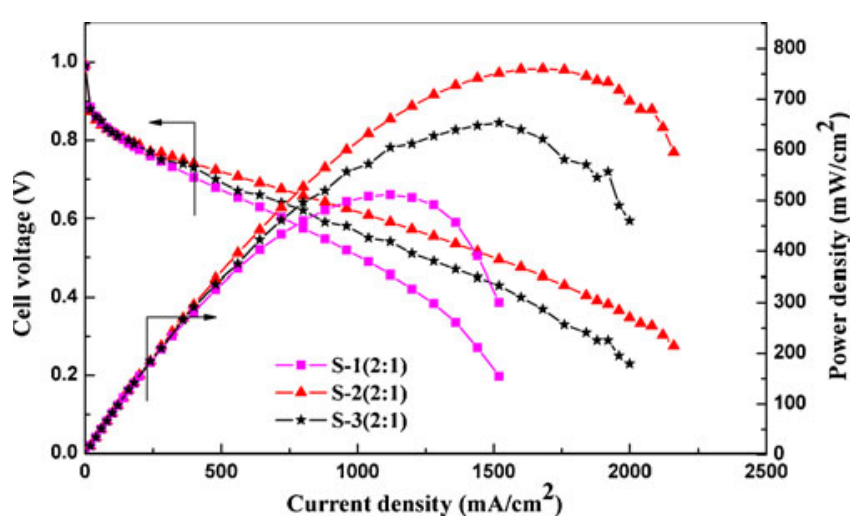

Figure 4. Steady-state performance of $\left(\mathrm{H}_{2} \mathrm{O}_{2}\right)$ PEFC cathodes with S-1(2:1), S-2(2:1) and S-3 (2:1). in relation to $S-1(2: 1)$ and $S-3(2: 1)$. In order to obtain the maximum activity for ORR, S-2 catalyst with varying atomic compositions of $\mathrm{Pt}$ to $\mathrm{Au}$, viz. 3:1 and 1:1, are prepared keeping the Pt content constant at $40 \mathrm{w} / \mathrm{o}$. Carbon-supported 40 wt. \% Pt (S-4) is also prepared by similar procedure for the sake of comparison.

Figure 5 shows TEM images for the S-2 catalyst with varying $\mathrm{Pt}$ to $\mathrm{Au}$ atomic ratios. It is seen that the $\mathrm{Pt}-\mathrm{Au}$ alloy nanoparticles with a narrow particle-size distribution are well dispersed on the surface of the carbon-support. The mean size of the metal nanoparticles on carbon-support is obtained by measuring 200 randomly-chosen particles in the magnified TEM images (table 2). In S-2 (3:1), the catalyst particles have narrower size-distribution than S-2 (2:1) and S-2 (1:1). The mean particle-size for S-2 catalysts increases with increasing Au content. These values are in good agreement with XRD (data not shown for the sake of brevity) data and the particle-size measured from XRD data using Scherrer equation are presented in table 2 . Although the XRD data for S-2(1:1) show nanometer-size particles, the TEM picture for S-2(1:1) shows ill-dispersed particles unlike other compositions. The high metal-to-support ratio in the catalyst is likely to induce such aggregation effects. Electron diffraction patterns for S-4 and S-2 catalysts with varying Pt to Au atomic ratio obtained from a selected area are presented in the inset of figure 5. The presence of a nano-sized alloy is evident through the ring pattern. However, S-2(1:1) alloy exhibits a broken ring due to clustered $\mathrm{Pt}-\mathrm{Au}$ alloy particles.

Quantitative analysis of platinum to gold atomic ratio is performed by ICP-OES (table 2) which indicates the bulk composition of the $\mathrm{Pt}-\mathrm{Au}$ alloy catalyst to be near the nominal value. Surface atomic compositions for the $\mathrm{Pt}-\mathrm{Au}$ alloy catalysts are also obtained by EDAX analysis. EDAX spectra for S-2 catalyst with varying $\mathrm{Pt}$ to Au atomic ratios, viz. S-2(1:1), S-2(2:1) and S-2(3:1), are obtained and it is found that the composition on the surface of the catalysts are closer to the nominal values. The EDAX compositions obtained for all the alloy catalysts prepared during this study are presented in table 2. The data suggest that the surface compositions of the $\mathrm{Pt}-\mathrm{Au}$ alloy catalysts are nearly similar to the bulk.

To analyse the electrochemical activity of S-2 with varying atomic ratios, a steady-state $\mathrm{CV}$ study is carried out in deaerated $0.5 \mathrm{M} \mathrm{H}_{2} \mathrm{SO}_{4}$ and data are presented in figure 6 . In the cyclic voltammogram, all the catalysts display the features of Pt-characteristic region. The ESA derived from area under adsorption peaks are presented in table 3. Lower values of ESA for S-2 catalysts are attributed to larger particle size for $\mathrm{Pt}-\mathrm{Au}$ than $\mathrm{Pt} / \mathrm{C}(\mathrm{S}-4)$. These values are in good agreement with TEM results.

To further examine the effect of composition of $\mathrm{Pt}$ to $\mathrm{Au}$ in S-2(2:1) catalyst towards ORR, LSV study is conducted using RDE at $1200 \mathrm{rpm}$ in oxygen-saturated $\mathrm{H}_{2} \mathrm{SO}_{4}$ with a scan rate of $3 \mathrm{mV} / \mathrm{s}$ and compared with S-4 (figure 7). S2(3:1) shows enhanced ORR activity in relation to $S-2(2: 1)$ and S-2(1:1), and all S-2 catalysts perform better than S-4. The electrode-kinetic parameters, viz. onset potential, kinetic 

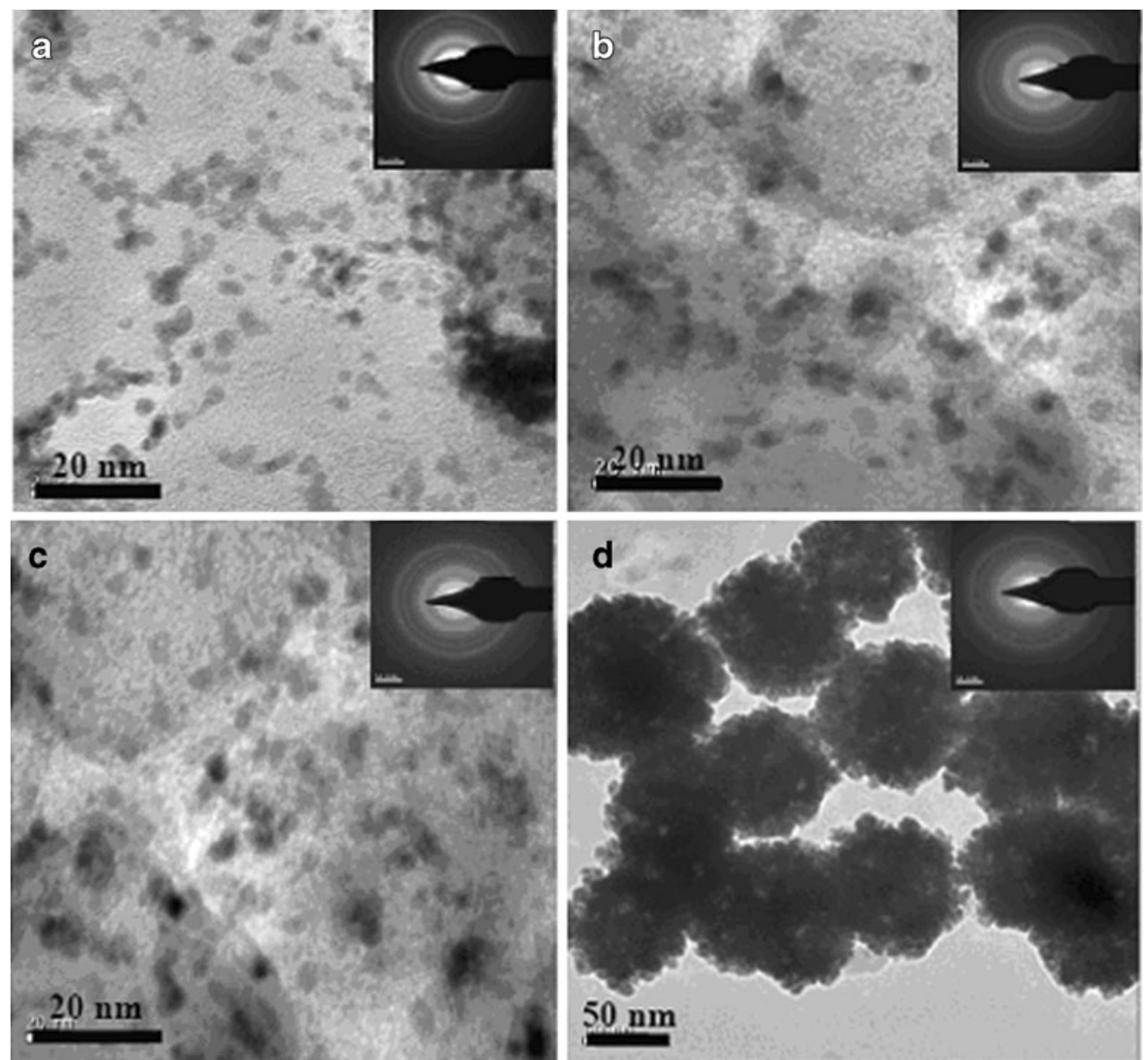

Figure 5. Transmission electron micrographs and electron diffraction patterns for $\mathbf{a}$. S-4, b. S-2 (3:1), c. S-2 (2:1), and d. S-2 (1:1) catalysts.

current-density at $0.6 \mathrm{~V}$ vs SCE and mass activity are presented in table 3. It is found that the onset potentials, mass activity and kinetic current density vary as: S-2 (3:1) > S-2 $(2: 1)>$ S-2 $(1: 1)>$ S-4.

The catalysts have also been performance tested in PEFCs. The cell polarization data for S-2 with varying $\mathrm{Pt}$ to $\mathrm{Au}$ atomic ratio, viz. $\mathrm{S}-2(3: 1), \mathrm{S}-2(2: 1)$ and $\mathrm{S}-2(1: 1)$, in a $\mathrm{H}_{2} / \mathrm{O}_{2}$ PEFC are compared with the PEFC employing S-4 catalyst electrodes and the data are presented in figure 8. PEFC cathodes employing S-2 with all the three atomic ratios perform

Table 2. Composition and structural parameters for S-4 and S-2 catalysts with varying atomic ratios.

Particle size, Particle size, Atomic ratio Atomic ratio $\begin{array}{lllll}\text { Catalyst } & \text { TEM }(n m) \quad \text { XRD (nm) } & \text { (ICP-OES) } \% & \text { (EDAX) } \%\end{array}$

\begin{tabular}{lcccc}
\hline S-2(3:1) & $4 \cdot 3$ & $4 \cdot 6$ & $74 \cdot 35: 25 \cdot 65$ & $71 \cdot 65: 28 \cdot 35$ \\
S-2(2:1) & 4.5 & 4.9 & $65 \cdot 8: 34 \cdot 2$ & $66 \cdot 25: 33 \cdot 75$ \\
S-2(1:1) & - & $5 \cdot 3$ & $49.44: 50.55$ & $50 \cdot 31: 49 \cdot 69$ \\
S-4 & $3 \cdot 5$ & 3.9 & - & - \\
\hline
\end{tabular}

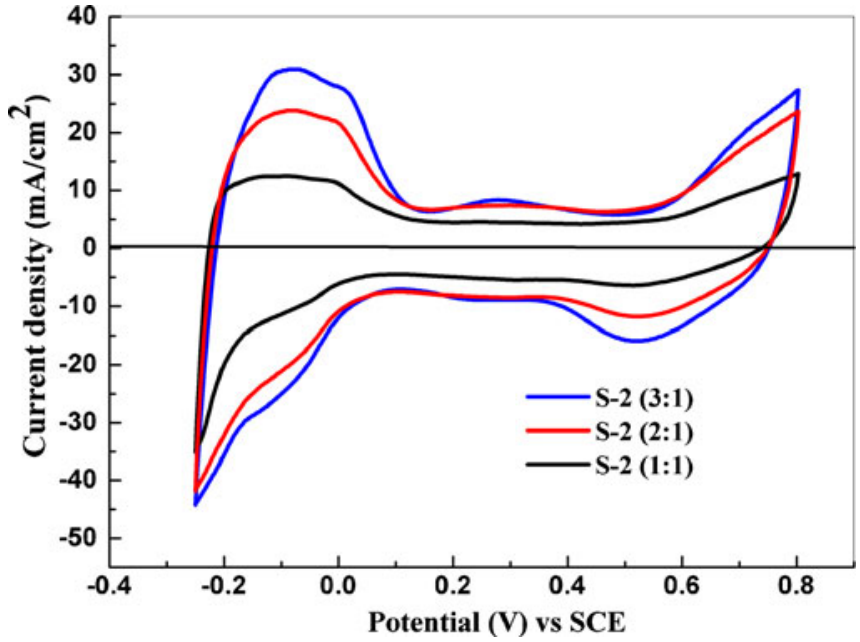

Figure 6. Steady-state cyclic voltammograms for S-2(3:1), S2(2:1), and S-2(1:1) catalysts in $\mathrm{N}_{2}$-saturated $0.5 \mathrm{M} \mathrm{H}_{2} \mathrm{SO}_{4}$.

better than the PEFC cathode with S-4. PEFC cathode comprising S-2(3:1) exhibits a power-density of $0.65 \mathrm{~W} / \mathrm{cm}^{2}$ at 
Table 3. Electrokinetic parameters for $\mathrm{S}-4$ and $\mathrm{S}-2$ catalysts with varying atomic ratios.

\begin{tabular}{|c|c|c|c|c|c|}
\hline Catalyst & $\begin{array}{c}\text { Charge } \\
Q_{\mathrm{H}}\left(\mathrm{mC} / \mathrm{cm}^{2}\right)\end{array}$ & $\begin{array}{l}\text { ESA } \\
\left(\mathrm{m}^{2} / \mathrm{g}\right)\end{array}$ & $\begin{array}{c}\text { Onset } \\
\text { potential } \\
(V \text { vs SCE })\end{array}$ & $\begin{array}{c}\text { Kinetic current } \\
\text { density @ } 0.6 \mathrm{~V} \text { vs } \\
\text { SCE }\left(\mathrm{mA} / \mathrm{cm}^{2}\right)\end{array}$ & $\begin{array}{c}\text { Mass activity @ } 0.6 \mathrm{~V} \\
\text { vs SCE (mA/g) }\end{array}$ \\
\hline S-2(3:1) & $105 \cdot 4$ & $100 \cdot 4$ & 0.757 & $5 \cdot 21$ & 10420 \\
\hline S-2(2:1) & $80 \cdot 5$ & $76 \cdot 7$ & 0.751 & 4.63 & 9260 \\
\hline S-2(1:1) & $47 \cdot 7$ & $45 \cdot 4$ & 0.748 & $3 \cdot 80$ & 7720 \\
\hline S-4 & $120 \cdot 6$ & $114 \cdot 8$ & 0.745 & $2 \cdot 81$ & 5620 \\
\hline
\end{tabular}

$0.6 \mathrm{~V}$ in relation to $0.53 \mathrm{~W} / \mathrm{cm}^{2}$ at the same cell voltage delivered by the PEFC cathode with S-4. Since the anode, electrolyte, reactant and testing conditions in all the PEFCs are identical, the enhanced performance of the former is merely due to Pt-Au alloy catalyst. These data support CV and LSV data.

Generally, the rate-determining step for ORR is breaking of $\mathrm{O}-\mathrm{O}$ bond to form water. The kinetics of the reaction depends on the degree of interaction of oxygen with catalyst adsorption sites. The enhanced electro-catalytic activity for Pt-Au alloy can be explained in the light of the electronic factor, viz. the change of the $d$-band vacancy in $\mathrm{Pt}$ upon alloying and/or by a geometric effect. These effects may enhance the reaction rate for oxygen adsorption and cleavage of $\mathrm{O}=\mathrm{O}$ bond during the reduction reaction. The enhanced catalytic activity of Pt-Au alloy is also elucidated in an earlier study using X-ray photoelectron spectroscopy (Selvarani et al 2009a). Au $4 f_{7 / 2}$ binding energy values for $\mathrm{Au}$ foil and $\mathrm{Au}$ in $\mathrm{Pt}-\mathrm{Au}$ catalyst are found to be $83.88 \mathrm{eV}$ and $83.50 \mathrm{eV}$, respectively. The shift in binding energy value suggests an intra-alloy charge transfer from $\mathrm{Pt}$

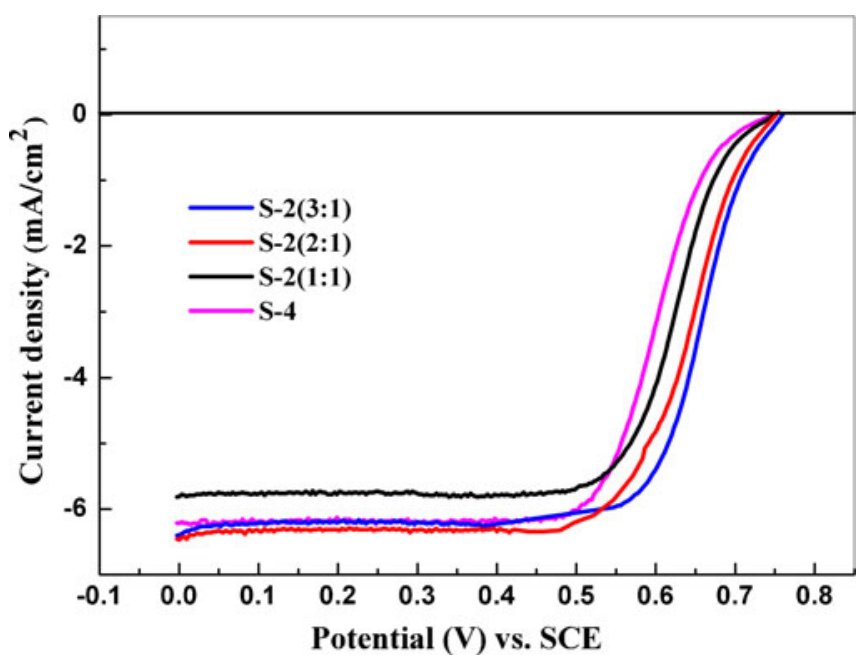

Figure 7. LSV measurements of S-4 and S-2 catalysts in $\mathrm{O}_{2}$ saturated $0.5 \mathrm{M} \mathrm{H}_{2} \mathrm{SO}_{4}$ for ORR at $1200 \mathrm{rpm}$ with a scan rate of $3 \mathrm{mV} / \mathrm{s}$. to $\mathrm{Au}$ due to the higher electro-negativity of $\mathrm{Au}(2 \cdot 54)$ in relation to $\mathrm{Pt}(2 \cdot 2)$. The higher electro-negativity for Au in relation to Pt increases $d$-orbital vacancies in Pt metal, resulting in increased electro-catalytic activity towards ORR. Density functional theory(DFT) calculations reflect a distorted geometry for $\mathrm{Pt}-\mathrm{Au}$ alloy catalyst in relation to pristine $\mathrm{Pt}$ and $\mathrm{Au}$ suggesting that Au atoms tend to occupy the corner positions (surface sites) in the presence of Pt (Selvarani et al 2009a). The orientation of Au atoms at surface sites with low coordination is attributed to (a) the relative cohesive energies, (b) electro-negativity values, and (c) electronic/steric effects. Data obtained from electronic parameters of modeled cluster indicate that the incorporation of $\mathrm{Au}$ to $\mathrm{Pt}$ matrix alters the distance of Pt-Pt and reduces the charge density on Pt. Furthermore, with increasing $\mathrm{Au}$ content in $\mathrm{Pt}-\mathrm{Au}$ (3:1) in relation to $\mathrm{Pt}-\mathrm{Au}(1: 1)$, the charge density on Pt decreases. It is noteworthy that Au atoms with low coordination numbers have higher-lying $d$ states more reactive and interact strongly with the adsorbate states (Lopez and Norskov 2002). In the light of the foregoing, $\mathrm{S}-2(1: 1)$ is expected to be superior than S-2(3:1). But contrary to this, S-2(1:1) with higher $\mathrm{Au}$ content than S-2(3:1) experiences lack of active Pt-sites on its surface for promoting ORR, resulting in reduced catalytic

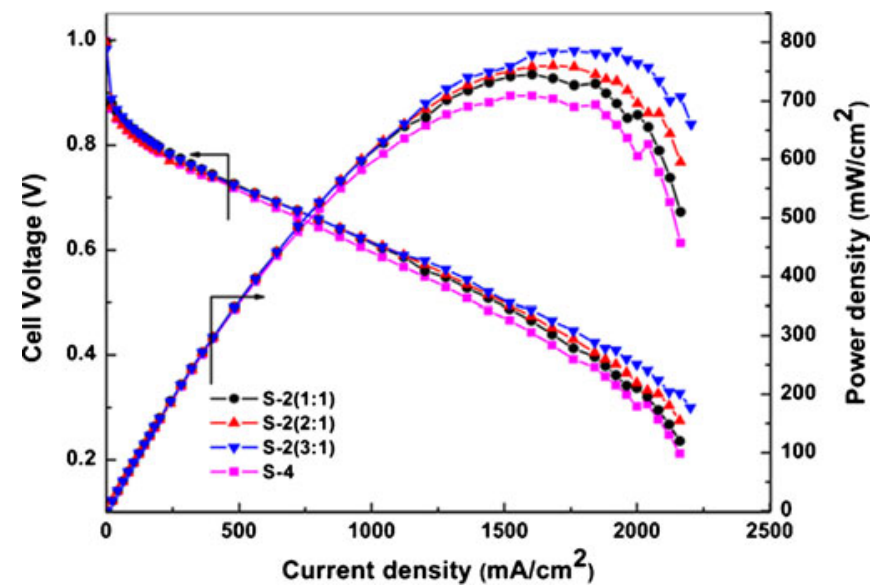

Figure 8. Steady-state performance of $\left(\mathrm{H}_{2}-\mathrm{O}_{2}\right)$ PEFCs with $\mathrm{S}-4$ and S-2 cathode catalysts. 
activity. These arguments favour the present experimental findings.

To further understand ORR on S-2(3:1) cathode catalyst, the electrode-kinetic parameters, viz. the number of electrons transferred during ORR and order of the reaction, have been obtained. ORR may either proceed through one-step 4-electron pathway or two-step 4-electron pathway through $\mathrm{H}_{2} \mathrm{O}_{2}$ intermediate. The low efficiency for a catalyst towards ORR is often attributed to the latter and is also considered to be responsible for degradation of polymer electrolyte membrane. Au is not an active catalyst for direct di-oxygen reduction to $\mathrm{H}_{2} \mathrm{O}$ as $\mathrm{ORR}$ on $\mathrm{Au}$ surface proceeds through two-step 4-electron pathway with hydrogen peroxide as the intermediate but for $\mathrm{Au}(100)$ plane and its vicinal surfaces in alkaline solutions (Adzic 1998). Pt reduces oxygen to water either through a 2-electron or a 4-electron process (Paulus et al 2001). Amelioration of ORR on Pt surfaces in presence of Au has been reported recently (Elhsissen et al 1999; Devarajan et al 2005; Luo et al 2005; Njoki et al 2005; Qian et al 2006; Hernandez-Fernandez et al 2008; Wang et al 2008, 2009; Liu et al 2009a, b; Ma et al 2010). However, the Au used in these studies is either used as a matrix to disperse the Pt sites or not as alloy particles.

Generally, LSV technique allows the determination of electrode-kinetic parameters for ORR (Paulus et al 2001). The ORR data obtained for the S-2(3:1) catalyst and S-4 at varying rotations, viz. 400, 800, 1200, 1600, 2000 and $2400 \mathrm{rpm}$. Both the catalysts show the current densities (current normalized to the geometric area of the electrode) to be proportional to rotation speed $(\omega)$. The number of electrons $(n)$ is generally calculated from the slope of Levich plots using the equation

$$
i_{\mathrm{d}}=0.62 n F A C D^{2 / 3} \gamma^{-1 / 6} \omega^{1 / 2} .
$$

In short (1) can be expressed as:

$$
i_{\mathrm{d}}=B \omega^{1 / 2},
$$

where $B=0.62 n F A C D^{2 / 3} \gamma^{-1 / 6}$ which is Levich slope, $F$ is faraday constant, $A$ the surface area of electrode, $C$ the bulk concentration of oxygen in the electrolyte, $D$ the diffusion coefficient of the reactant in electrolyte, $\gamma$ the kinematic viscosity of solution and $\omega$ the angular frequency of rotation. Generally, under the mass-transfer-limiting condition, the Levich slope is constant. However, in the present study, when cathodic limiting current-densities are plotted vs $\omega^{1 / 2}$ a slightly curved line is observed. Hence, the inverse Levich plot, i.e. $i^{-1}$ vs $\omega^{-1 / 2}$, is used to obtain the kinetic parameters, which is generally referred to as Koutecky-Levich $(\mathrm{K}-\mathrm{L})$ expression and is a straight line with non-zero intercepts.

Gloaguen et al (1998) and Gojkovic et al (1998) have demonstrated a strong diffusion-resistance while using Nafion film over the catalyst layer in Koutecky-Levich type analysis of the ORR currents. Since, their preparation method results in a relatively thick catalyst-layer $(1-7 \mu \mathrm{m})$ with a

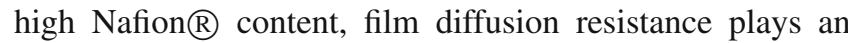
important role. By contrast, in the present study, the Nafion ${ }^{\circledR}$ ionomer is dispersed in the catalyst ink and thin layer of catalyst is deposited on substrate electrode (Paulus et al 2001). It is established that Nafion film diffusion resistance is negligible within the accessible current-density range up to $3600 \mathrm{rpm}$ for the film thickness $<0.2 \mu \mathrm{m}$. Accordingly, the kinetic current-densities can be extracted directly using the unmodified mass-transport correlation, viz. $\mathrm{K}-\mathrm{L}$ equation, as follows:

$$
\begin{aligned}
& 1 / i=1 / i_{\mathrm{k}}+1 / i_{\mathrm{d}}, \\
& 1 / i=1 / i_{\mathrm{k}}+1 /\left(B \omega^{1 / 2}\right) .
\end{aligned}
$$

In (3), $i_{\mathrm{k}}$ (kinetic current) represents the current in the absence of any mass-transfer effects i.e. the current that would flow under the kinetic limitation if the mass transfers are efficient enough to keep the concentration at the electrode surface equal to the bulk value, regardless of the electrode reaction. Clearly, $i / \omega^{1 / 2}$ is constant only when $i_{\mathrm{k}}$ is very large. Otherwise, a plot of $i$ vs $\omega^{1 / 2}$ will not be a straight line and would tend toward the limit $i=i_{\mathrm{k}}$ as $\omega^{1 / 2} \rightarrow \infty$. But, a plot of $1 / i$ vs $1 / \omega^{1 / 2}$ should be linear and can be extrapolated to $\omega^{-1 / 2}=0$ to yield $1 / i_{\mathrm{k}}$. Figure 9 represents the inverse current density $\left(i^{-1}\right)$ as a function of the inverse of the square root of the rotation rate $\left(\omega^{-1 / 2}\right)$, i.e. the so-called $\mathrm{K}-\mathrm{L}$ plot. The linearity and the parallel character of these plots are suggestive of first-order kinetics with respect to molecular oxygen. From the K-L plots, S-2(3:1) catalyst shows enhanced kinetic current-density $\left(i_{\mathrm{k}}\right)$ in relation to $\mathrm{Pt} / \mathrm{C}(\mathrm{S}-4)$, which clearly indicates that the incorporation of $\mathrm{Au}$ into $\mathrm{Pt}$ matrix improves ORR.

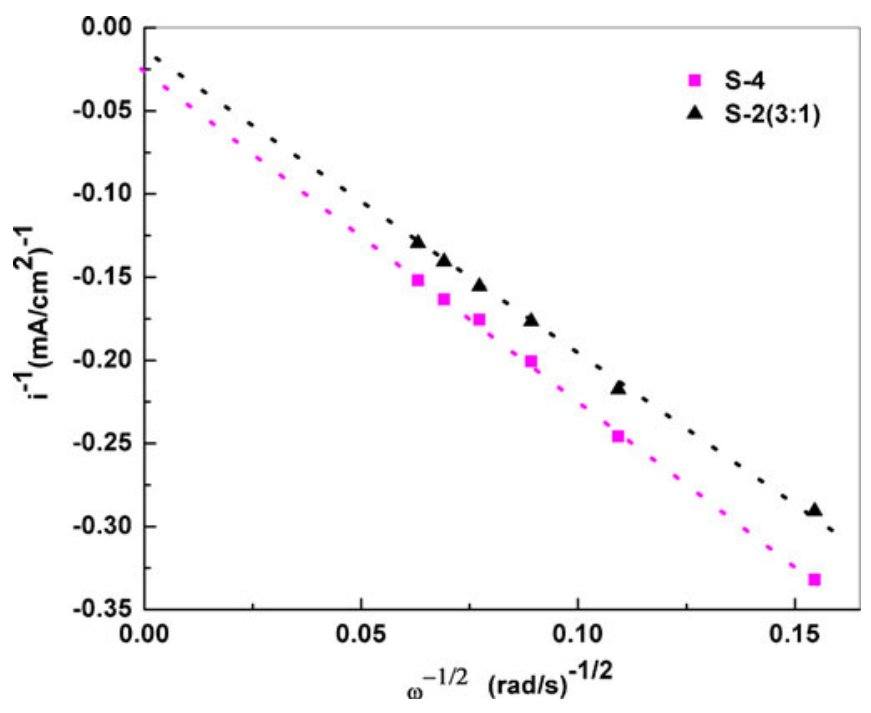

Figure 9. Levich-Koutecky plots for S-2 (3:1) and S-4 catalysts at $0.46 \mathrm{~V}$ vs SCE. 
In general, the efficiency of catalyst can be obtained from the value of $n$ during ORR. The actual number of electrons transferred by each oxygen molecule is calculated from the following values: (i) diffusion coefficient of $\mathrm{O}_{2}(D)$ as 1.93 $\times 10^{-5} \mathrm{~cm}^{2} \mathrm{~s}^{-1}$ (Markovic et al 1999), (ii) kinematic viscosity of the solution $(\gamma)$ as $1.009 \times 10^{-2} \mathrm{~cm}^{2} / \mathrm{s}$ (Markovic et al 1999) and (iii) concentration of dissolved $\mathrm{O}_{2}$ in solution (C) as $1.26 \times 10^{-3} \mathrm{~mol} \mathrm{~L}^{-1}$ (Lide 1995). From the slope of K-L plot (B), the value of $n$ is calculated to be 4 for the S-2(3:1) catalyst. These values are higher than that for S4 system. The S-2 catalyst reported here promotes the one step 4-electron transfer ORR. Furthermore, the ring current for $\mathrm{Pt}-\mathrm{Au}$ catalyst shows negligible generation of hydrogen peroxide akin to that reported by Zhang et al (2007) suggesting a four-electron reduction of oxygen to water. As the S-2 catalysts reported here promote the 4-electron-ORR through one step reduction of di-oxygen to water without generation of peroxide, higher durability is also anticipated for the membrane electrolyte.

\section{Conclusions}

Carbon-supported $\mathrm{Pt}-\mathrm{Au}$ alloy is prepared by three different methods, viz. colloidal, impregnation and microemulsion. $\mathrm{Pt}-\mathrm{Au}$ catalysts prepared through colloidal and micro-emulsion methods result in homogenous solid solutions, while the catalyst prepared by impregnation method results in segregated $\mathrm{Pt}$ and $\mathrm{Au}$ particles. Among the three methods of preparation of $\mathrm{Pt}-\mathrm{Au}$ catalyst, the catalyst prepared by colloidal method is found to perform better towards ORR in relation to the catalyst impregnation and microemulsion. Among the various $\mathrm{Pt}-\mathrm{Au} / \mathrm{C}$ catalysts prepared by colloidal method with varying atomic ratios of $\mathrm{Pt}$ to $\mathrm{Au}, \mathrm{S}$ 2(3:1) i.e. Pt-Au (3:1)/C, shows maximum electrochemical activity towards ORR.

\section{Acknowledgements}

Financial support from CSIR, New Delhi, through a suprainstitutional project under EFYP is gratefully acknowledged.

\section{References}

Adzic R R 1998 in Electrocatalysis (eds) J Lipkowski and P N Ross (New York: Wiley-VCH) p. 197

Antolini E, Salgado J R C and Gonzalez E R 2005 J. Electroanal. Chem. $\mathbf{5 8 0} 145$

Berg C, Venvik H J, Strisland F, Ramstad A and Borg A 1998 Surf. Sci. 4091

Bockris J O M and Srinivasan S 1969 Fuel cells: Their electrochemistry (USA: McGraw-Hill Book Company)

Bond G C 2007 Platinum Metals Rev. 5163

Devarajan S, Bera P and Sampath S 2005 J. Collod Interf. Sci. 290 117
El-Deab M S and Osaka T 2002a Electrochem. Commun. 4288

El-Deab M S and Osaka T 2002b Electrochim. Acta 474255

El-Deab M S and Osaka T 2003 J. Electroanal. Chem. 553107

Elhsissen K T, Bonet F, Silvert P Y and Urbina R H 1999 J. Alloys Compd 29296

Fernandez J L, Raguveer V, Manthiram A and Bard A J 2005 J. Am. Chem. Soc. 12713100

Gasteiger H A, Kocha S S, Sompalli B and Wagner F T 2005 Appl. Catal. B. Environ. 569

Gloaguen F, Convert P, Gamburzev S, Velev O A and Srinivasan S 1998 Electrochim. Acta $\mathbf{4 3} 3767$

Gojkovic S L, Zecevic S K and Savinell R F 1998 J. Electrochem. Soc. 1453713

Gong Y, Yeboah Y D, Lvov S N, Balashov V and Wang Z $2007 \mathrm{~J}$. Electrochem. Soc. 154 B560

Goodenough J B, Manoharan R, Shukla A K and Ramesh K V 1989 Chem. Mater. 1391

Gottesfeld S and Zawodzinski T A 1997 in Advances in electrochemical science and engineering (eds) R C Alkire et al (Weinheim: Wiley-VCH), Ch. 4, Vol. 5

Haruta M 1997 Catal. Today 36153

Haruta M 2005 Nature 4371098

Hernandez-Fernandez P, Rojas S, Ocon P, Gomez de la Fuente J L, San Fabian J, Sanza J, Pena M A, Garcia-Garcia F J, Terreros P and Fierro J L G 2007 J. Phys. Chem. C111 2913

Hernandez-Fernandez P, Rojas S, Ocon P, de Frutos A, Figueroa J M, Terreros P, Pena M A and Fierro J L G 2008 J. Power Sources 1779

Hughes M D et al 2005 Nature 4371132

Janssens T V W, Carlsson A, Puig-Molina A and Clausen B S 2006 J. Catal. 240108

Kristian N and Wang X 2008 Electrochem. Commun. 1012

Li H, Xin Q, Li W, Zhou Z, Jiang L, Yang S and Sun G 2004 Chem. Commun. 252776

Lide D R 1995 CRC handbook of chemistry and physics (Boca Raton, FL: CRC Press) 75th ed.

Lima F H B, Lizcano-Valbuena W H, Teixeira-Neto E, Nart F C, Gonzalez E R and Ticianelli E A 2006 Electrochim. Acta 52 385

Liu C W, Wei Y C and Wang K W 2009a J. Colloid Interf. Sci. 336 654

Liu C W, Wei Y C and Wang K W 2009b Electrochem. Commun. 111362

Lopez N and Norskov J K 2002 J. Am. Chem. Soc. 12411262

Luo J et al 2005 Catal. Today 99291

Luo J, Njoki P N, Lin Y, Wang L and Zhong C J 2006 Electrochem. Commun. 8581

Ma Y, Zhang H, Zhong H, Xu T, Jin H and Geng X 2010 Catal. Commun. 11434

Markovic N M, Gasteiger H A, Grgur B N and Ross P N 1999 J. Electroanal. Chem. 467157

Mathiyarasu J and Phani K L N 2007 J. Electrochem. Soc. 154 B1100

Mott D, Luo J, Njoki P N, Lin Y, Wang L and Zhong C J 2007 Catal. Today 122378

Njoki P N, Luo J, Wang L, Maye M M, Quaizar H and Zhong C J 2005 Langmuir 211623

Paulus U A, Schmidt T J, Gasteiger H A and Behm R J 2001 J. Electroanal. Chem. 495134

Pourbaix M 1974 Atlas of electrochemical equilibria in aqueous solutions (USA; National Association of Corrosion Engineers) 
Qian L, Sha Y and Yang X 2006 Thin Solid Films 515 1349

Selvarani G, Vinod Selvaganesh S, Krishnamurthy S, Kiruthika G V M, Sridhar P, Pitchumani S and Shukla A K 2009a J. Phys. Chem. C113 7461

Selvarani G, Maheswari S, Sridhar P, Pitchumani S and Shukla A K 2009b J. Electrochem. Soc. 156 B1354

Shao M H, Huang T, Liu P, Zhang J, Sasaki K, Vukmirovic M B and Adzic R R 2006a Langmuir 2210409
Shao M H, Sasaki K and Adzic R R 2006b J. Am. Chem. Soc. 128 3526

Wang J, Yin G, Wang G, Wang Z and Gao Y 2008 Electrochem. Commun. 10831

Wang J, Yin G, Liu H, Li R, Flemming R L and Sun X $2009 \mathrm{~J}$. Power Sources 194668

Xu Y and Mavrikakis M 2003 J. Phys. Chem. B107 9298

Yuan W, Scott K and Cheng H 2006 J. Power Sources 163323

Zhang J, Sasaki K, Sutter E and Adzic R R 2007 Science 315220 